\title{
Cell line-dependent variability in HIV activation employing DNMT inhibitors
}

Guerau Fernandez ${ }^{1}$, Steven L Zeichner ${ }^{1,2^{*}}$

\begin{abstract}
Long-lived reservoirs of Human Immunodeficiency Virus (HIV) latently infected cells present the main barrier to a cure for HIV infection. Much interest has focused on identifying strategies to activate HIV, which would be used together with antiretrovirals to attack reservoirs. Several HIV activating agents, including Tumor Necrosis Factor alpha (TNF $\alpha$ ) and other agents that activate via NF-kB are not fully effective in all latent infection models due to epigenetic restrictions, such as DNA methylation and the state of histone acetylation. DNA methyltransferases (DNMT) inhibitors like 5-aza-2'deoxycytidine (Aza-CdR) and histone deacetylase (HDAC) inhibitors like Trichostatin A (TSA) have been proposed as agents to enhance reactivation and have shown activity in model systems. However, it is not clear how the activities of DNMT and HDAC inhibitors range across different latently infected cell lines, potential models for the many different latently infected cells within an HIV patient. We determined HIV activation following treatment with TNF $\alpha$, TSA and Aza-CdR across a range of well known latently infected cell lines. We assessed the activity of these compounds in four different Jurkat T cell-derived J-Lat cell lines (6.3, 8.4, 9.2 and 10.6), which have a latent HIV provirus in which GFP replaces Nef coding sequence, and ACH-2 and J1.1 (T cell-derived), and U1 (promonocyte-derived) cell lines with full-length provirus. We found that Aza-CdR plus TNF $\alpha$ activated HIV at least twice as well as TNF $\alpha$ alone for almost all J-Lat cells, as previously described, but not for J-Lat 10.6, in which TNF $\alpha$ plus Aza-CdR moderately decreased activation compared to TNF $\alpha$ alone. Surprisingly, a much greater reduction of TNF $\alpha$-stimulated activation with Aza-CdR was detected for ACH-2, J1.1 and U1 cells. Reaching the highest reduction in U1 cells with a 75\% reduction. Interestingly, Aza-CdR not only decreased TNF $\alpha$ induction of HIV expression in certain cell lines, but also decreased activation by TSA. Since DNMT inhibitors reduce the activity of provirus activators in some HIV latently infected cell lines the use of epigenetic modifying agents may need to be carefully optimized if they are to find clinical utility in therapies aimed at attacking latent HIV reservoirs.
\end{abstract}

\section{Findings}

Despite the effectiveness of Highly Active Antiretroviral Therapy (HAART) for Human Immunodeficiency Virus type 1 (HIV-1) infection, patients cannot be cured due to the persistence of long-lived reservoirs of cells latently infected with HIV ([1-5] and reviewed in [6-11]). Much interest has focused on attacking this reservoir of HIV latently infected cells. A potentially useful strategy, sometimes termed "shock and kill" [12], aims to attack the latent reservoir treating patients with HIV-activating agents to stimulate HIV replication in the latently infected cells while blocking new infection of cells with antiretrovirals.

\footnotetext{
* Correspondence: zeichner@gwu.edu

'Center for Cancer and Immunology Research, Children's Research Institute,

Children's National Medical Center, Washington DC, USA

Full list of author information is available at the end of the article
}

One activation approach employs agents like phorbol esters (e.g 12-O-Tetradecanoylphorbol-13-acetate (TPA), prostratin) [13], interleukins (IL-2, IL-7) [14-18] and cytokines (e.g. tumor necrosis factor alpha (TNFo)) [19] that directly activate HIV gene expression via wellknown transcriptional activation pathways, like NF- $\kappa \mathrm{B}$, but many such agents are toxic or incompletely effective in vivo $[14,16,20,21]$. Other approaches target the provirus' epigenetic environment, employing histone deacetylase (HDAC) inhibitors (HDACIs) like trichostatin A (TSA) [22,23], suberoylanilide hydroxamic acid (SAHA) $[22,24]$, sodium butyrate $[25,26]$, and valproic acid $[27,28]$, and/or DNA methyltransferase (DNMT) inhibitors (DNMTIs) like 5-aza-2'deoxycytidine (Aza-CdR) [29], with some strategies combining approaches [30] (and reviewed in [6,31]). In addition, to increase the efficiency of viral activators, combining the use of activators
C Biomed Central

(c) 2010 Fernandez and Zeichner; licensee BioMed Central Ltd. This is an Open Access article distributed under the terms of the Creative Commons Attribution License (http://creativecommons.org/licenses/by/2.0), which permits unrestricted use, distribution, and reproduction in any medium, provided the original work is properly cited. 
with compounds aimed at limiting the toxicity of the activator, as shown with buthionine sulfoximine [32] may play a major role in optimizing treatment strategies.

Nucleosomes occupy specific positions on the HIV LTR $[22,33,34]$, with the nucleosome occupying the position termed 'nuc-1' at a regulatory region of the LTR 610 to $720 \mathrm{bp} \mathrm{3'} \mathrm{to} \mathrm{the} \mathrm{transcription} \mathrm{start} \mathrm{site} \mathrm{hav-}$ ing significant inhibitory effects on HIV expression. Chromatin condensed around nuc-1 in its deacetylated form presents a block to HIV expression. Following hyperacetylation and chromatin remodeling, mediated by the recruitment of histone acetylases by transcription factors binding directly or indirectly to the LTR, or by Tat, the nuc-1 block is removed [22,33,35-37]. HDACIs, by shifting histones to a more acetylated state facilitate remodeling and removal of the block $[38,39]$. DNMTIs likely activate HIV because, at least in some cells, the LTR contains two CpG islands (particularly island 2) that can be hypermethylated and the hypermethylated DNA can recruit methyl-CpG binding domain (MDB) protein family members, notably MDB2. MDB2 recruited to the LTR can serve a bridging function between DNA and chromatin-modifying factors, such as HDACs [29]. Several studies linked retroviral promoter CpG methylation with transcription inactivation [40-42] and cellular gene silencing [43]. DNMTIs can moderately activate HIV alone, but in some systems they significantly enhance agents, like TNF $\alpha$, that directly activate the HIV LTR, probably because activation is limited due to proviral DNA hypermethylation $[29,44,45]$.

While DNMTIs and HDACIs significantly enhance HIV activation in some latently infected cells, their ability to enhance activation across a wider range of latently infected cells is currently unknown. The breadth of activating ability is important, since complete or close-to complete eradication of latently infected cells may be required to cure HIV infection. To better assess the breadth of activity of activators representative of both direct activators and activators acting via epigenetic effects we surveyed the ability of three prototypical HIV activating agents, the DNMTI Aza-CdR $(2.5 \mu \mathrm{M})$, the HDACI TSA $(1.5 \mu \mathrm{M})$, and TNF $\alpha(10 \mathrm{ng} / \mathrm{ml})$, activating via NF- $\kappa \mathrm{B}$, in a panel of widely used HIV latently infected model cell lines, including the J-Lat series derived from Jurkat T-cells [46], J1.1 [47], also a Jurkat derivative, $\mathrm{ACH}-2$ [48], derived from the A3.01 T lymphocytoid cell line, and U1 [49], derived from the U937 promonocytic cell line. The concentrations used for TSA and TNF $\alpha$ were optimized to obtain the best activation profile in combination with Aza-CdR. A dose response curve with J-Lat 6.3 cells was performed to determine the minimum concentration required where the activation reached a plateau (data not shown). We employed this plateau concentration in subsequent studies to assess the effects of combined treatments with different agents used at their maximally effective concentrations, since the object of any latency activation strategy would be to determine how to achieve a maximal degree of provirus activation.

J-Lat cells harbor an HIV provirus containing the Green Fluorescent Protein (GFP) ORF instead of nef and a frameshift mutation in env [46]. With GFP under the control of the HIV LTR, activation is conveniently monitored via flow cytometry. HIV production in J-Lat cells can also be determined by p24 antigen (p24) quantification. Different J-Lat lines exhibit different activation patterns when treated with TNF $\alpha$, likely due to different integration sites and accompanying epigenetic states [46]. J-Lat cells have contributed significantly to latency studies, including the identification of the methyl-CpG binding domain protein 2 (MBD2), a transcriptional repressor that binds to methylated DNA, as a regulator of HIV latency, which suggested that DNMTIs like AzaCdR might activate latent provirus [29]. Moreover, LTR demethylation, after Aza-CdR treatment, correlated with a synergistic increase of proviral activation when combined with TNFa in J-Lat 6.3, 8.4, 9.2 and 15.4. ACH-2, $\mathrm{U} 1$ and J1.1 harbor full-length proviruses, without GFP replacing coding sequence (although J1.1 has defects in signalling through $\mathrm{CD} 3, \mathrm{ACH}-2$ has a point mutation in the Tat responsive element (TAR) [50], and U1 contains mutations in Tat [51]). Flow cytometric evaluation of activation is not possible in these lines, but they can be monitored using assays for HIV gene products (e.g. p24).

Before embarking on a survey of the activators across cell lines, we undertook further optimization experiments, initially performing order-of-addition experiments using J-Lat 6.3 (Fig.1), in which Aza-CdR had been shown to enhance activation mediated by TNFa [29], since inhibiting DNA methylation well before addition of the direct transcriptional activator TNF $\alpha$ could be required for maximal activation. Detection and quantification of GFP positive cells from a live-gated population was performed at $48 \mathrm{~h}$ using a FACScalibur cytometer (BD Biosciences, San Jose CA), analyzed with Cell Quest Pro software (BD Biosciences, San Jose CA). As has been previously reported, we found that Aza$\mathrm{CdR}$ alone did not activate [29], but TNF $\alpha$ alone produced significant increases in GFP positive cells, and Aza-CdR enhanced activation with TNF $\alpha$ treatment. We calculated the fold increase of activation due to Aza$\mathrm{CdR}$, that is the activation observed with TNF $\alpha$ plus Aza-CdR divided by the activation with TNF $\alpha$ alone (TNF $\alpha+$ Aza-CdR/TNF $\alpha$, (FI-Aza)), which expresses the fold increase due to the addition of Aza-CdR. FI-Aza showed that the greatest activation occurred when J-Lat 


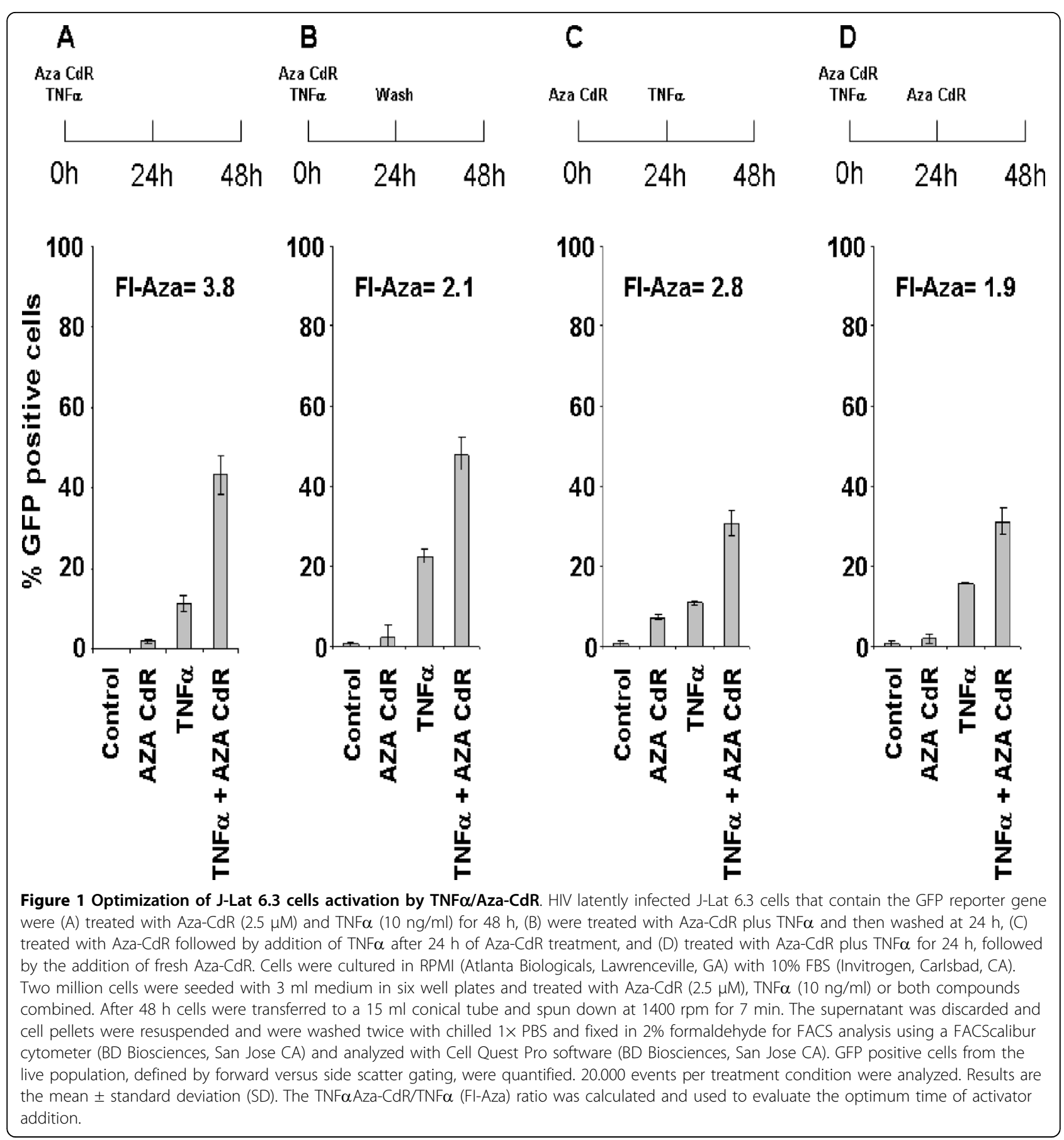

6.3 cells were treated with both compounds simultaneously (FI-Aza:3.8). Although there were differences in the extent of activation that depended on the order of addition, Aza-CdR always enhanced activation of J-Lat 6.3 by TNF $\alpha$, with FI-Aza ranging between 3.8 and 1.9.

To determine when Aza-CdR most enhanced TNF $\alpha$ or TSA activation, a time-course experiment was performed using J-Lat 6.3 cells. Percent GFP positive cells using FACS analysis (Fig. 2A) and p24 production using an enzyme-linked immunosorbent assay (ELISA) (Perkin Elmer, Waltham, MA) (Fig. 2B) were determined for all time points and treatment conditions. Aza-CdR in combination with TNF $\alpha$ reached its maximum effect at $48 \mathrm{~h}$ post-induction when per cent GFP positive cells where quantified. Moreover, p24 production did not increase significantly beyond $48 \mathrm{~h}$, losing Aza-CdR's enhancing effect when combined with TNF $\alpha$ at later time points. Due to the lack of synergy between TSA and Aza-CdR 


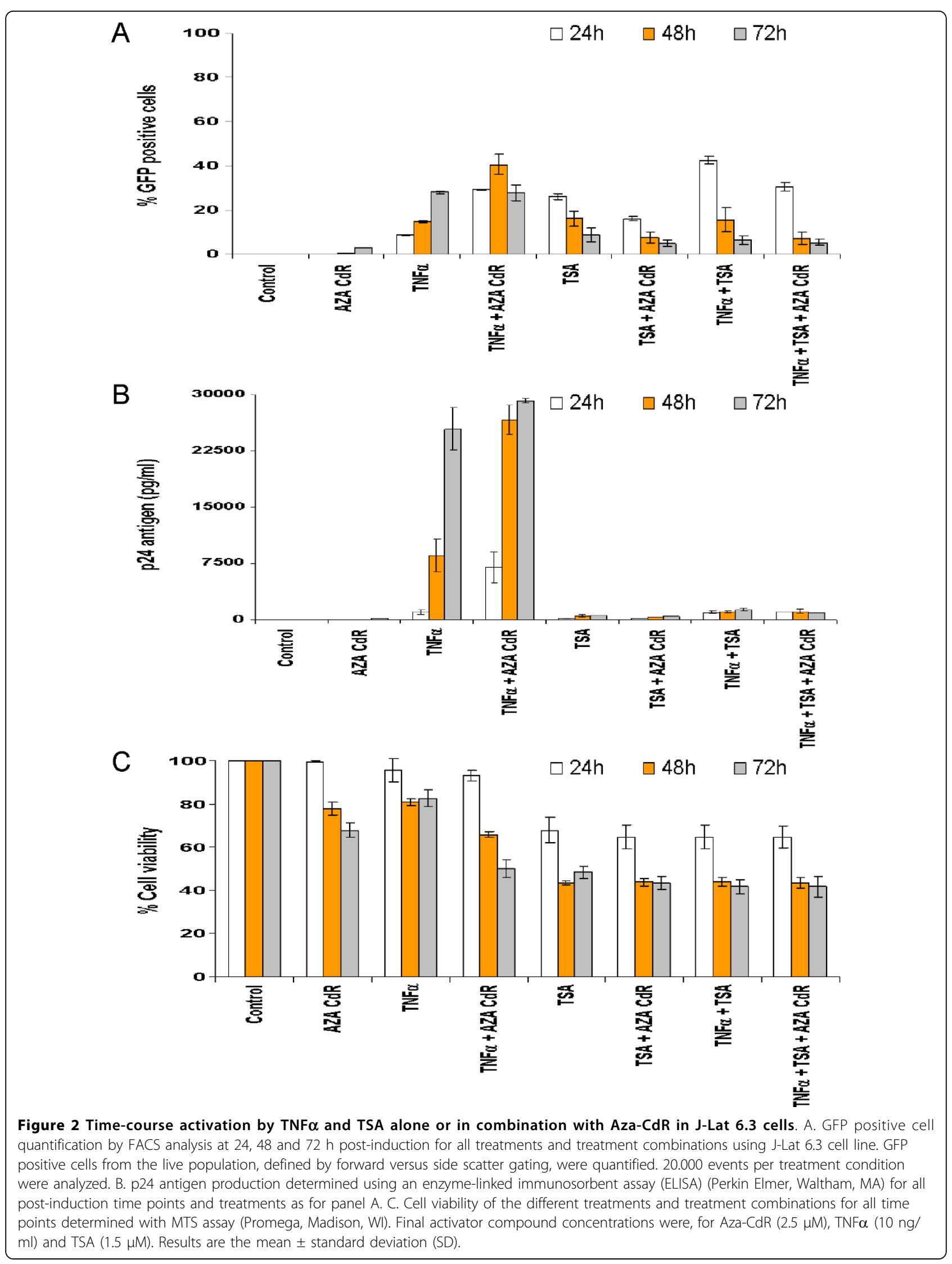


we determined $48 \mathrm{~h}$ to be the best time point to analyze further data based on TNF $\alpha$ plus Aza-CdR results. Cell viability for all time points and treatment conditions (Fig. 2C) were performed using MTS assay (Promega, Madison, WI). TNF $\alpha$ alone does not strongly activate J-Lat 6.3, 8.4 and 9.2 cells, as shown in Fig. 3A, and as reported [29]. TNF $\alpha$ can, at most, achieve $20 \%$ activation in these three cell lines. In contrast, in J-Lat 10.6, TNF $\alpha$ activates $\sim 80 \%$ of the cells, which enabled us to determine the effect of combining Aza-CdR with TNFa and TSA when the provirus is highly activated by TNFa. Surprisingly, the combination of Aza-CdR and TNF $\alpha$ did not increase or maintain activation in J-Lat 10.6, but instead moderately decreased activation ( $\mathrm{p} \leq$ 0.1 ) (Fig. 3B) in per cent GFP positive cells while activation from the combination of Aza-CdR and TNF $\alpha$ was significantly lower when $\mathrm{p} 24$ was determined $(\mathrm{p} \leq 0.05)$ (Fig. 3C). The reduction of activation in J-Lat 10.6 suggested that Aza-CdR could have, in some latently infected cells, a detrimental effect when combined with an activator, particularly when activation via other pathways, such as those stimulated by TNF $\alpha$, is great (Fig. 3C). Cell viability did not differ between TNF $\alpha$ and Aza-CdR, alone or in combination (Fig. 3D), so cell toxicity could not account for the observations. Of note, we did not detect a synergistic effect when TNF $\alpha$ and TSA were combined when percent GFP positive cells were quantified. As shown in the time-course experiment in Fig. 2 this synergy can be detected in earlier time points but not at $48 \mathrm{~h}$ post-induction when Aza-CdR reaches maximal effect. When $\mathrm{p} 24$ production is determined, we only could see this TSA-TNF $\alpha$ synergy in J-Lat 8.4 cells because TNF $\alpha$ activation in this cell line is strongly blocked (Fig. 3C).

To assess how the combinations of Aza-CdR, TNFa, and TSA affect HIV activation in other HIV latently infected cells, we studied the ability of these agents, alone and together, to activate HIV in ACH-2, U1 and J1.1 cells (Fig. 4A), other lines in which TNFa strongly activates HIV expression [52]. Since these cells harbor a latent HIV provirus that does not have nef replaced with GFP, we assessed activation by measuring p24 48 $\mathrm{h}$ after treatment with the activators using ELISA (Perkin Elmer, Waltham, MA). TNF $\alpha$ powerfully activated HIV expression in these cells, as previously described, but as we observed with J-Lat 10.6, treating ACH-2, $\mathrm{U} 1$ and J1.1 cells with Aza-CdR significantly decreased activation by TNF $\alpha$, from $23 \%$ (J1.1, p $\leq 0.05$ ) to $40 \%$ (ACH-2, p $\leq 0.05$ ), to 75\% (U1, p $\leq 0.05$ ). In ACH-2 cells, but not in any other of the cell lines studied, Aza-CdR also significantly decreased activation following treatment with TSA alone $(57 \%, \mathrm{p} \leq 0.05)$, or TSA + TNF $\alpha(45 \%, p \leq 0.05)$. Impaired cell viability, as with $\mathrm{J}$-Lat cells, could not explain this reduction in activation (Fig. 4B). Thus, in certain circumstances, a DNMTI can decrease activation by agents acting both through the NF- $\kappa \mathrm{B}$ pathway and mediated by an HDACI. However, a decrease in activation produced by Aza-CdR was not observed in all the non-J-Lat cell lines under all conditions. In J1.1 cells, Aza-CdR did not decrease activation by TSA or TSA plus TNFa. Overall, the ability of the DNMTI Aza-CdR to help activate HIV replication (or to inhibit the activation produced by other agents) exhibited a strong cell line dependence: In U1 and J1.1 cell lines, Aza-CdR inhibited activation by TNF $\alpha$, but not by TSA or TNF $\alpha$ plus TSA, while in ACH-2 cells Aza-CdR inhibited activation by both TNF $\alpha$ and TSA when used alone or in combination. Table 1 summarizes the effect of Aza$\mathrm{CdR}$ and TNF $\alpha$ when added simultaneously in all latently infected cells tested, highlighting that the effects due to the combination of agents may be detrimental or helpful, depending on the cell line studied. The data presented in this report complements the findings by Kauder et al. [29] and Blaskova et al. [44] regarding the effects of Aza-CdR in activating latently infected cells. In those studies, cell lines $\mathrm{H} 12$ and 2D12 [44] and all the J-Lat clones except for A2 clone [29] showed increased activation with Aza-CdR used in combination with TNF $\alpha$ in comparison with TNF $\alpha$ alone (the A2 clone showed the same levels of activation with or without Aza-CdR). The detrimental effect we observed with Aza-CdR in certain latently infected cell lines induced by viral activators like TNF $\alpha$ (ACH2, J1.1 and U1) highlights the complexity of HIV reactivation, the importance of studies utilizing a broad range of cell lines, and the broad range of effects that may be observed in different infected cells.

The differential effects on HIV activation of epigenetic agents may not be entirely unexpected, since the chromatin structure of the LTR can differ for the proviruses integrated into one cell line or another [53]. It will require much additional work to understand the mechanisms responsible for the differential responses to epigenetic activators, but a few potential explanations may be considered. Aza-CdR may have complicated effects, since the activation of some genes may inhibit others [54-56], so differences in the methylation and hence activation state of cellular genes in the latently infected cell lines could account for the differences in activation observed with Aza-CdR: In J-Lat 6.3, 8.4 and 9.2 cells, Aza-CdR may have direct effects, leading to the demethylation of the LTR, enhancing activation, while in the other lines Aza-CdR may help activate other cellular genes that directly or indirectly inhibit HIV activation, since differential expression of certain cellular genes can be associated with the maintenance of latency $[57,58]$. 

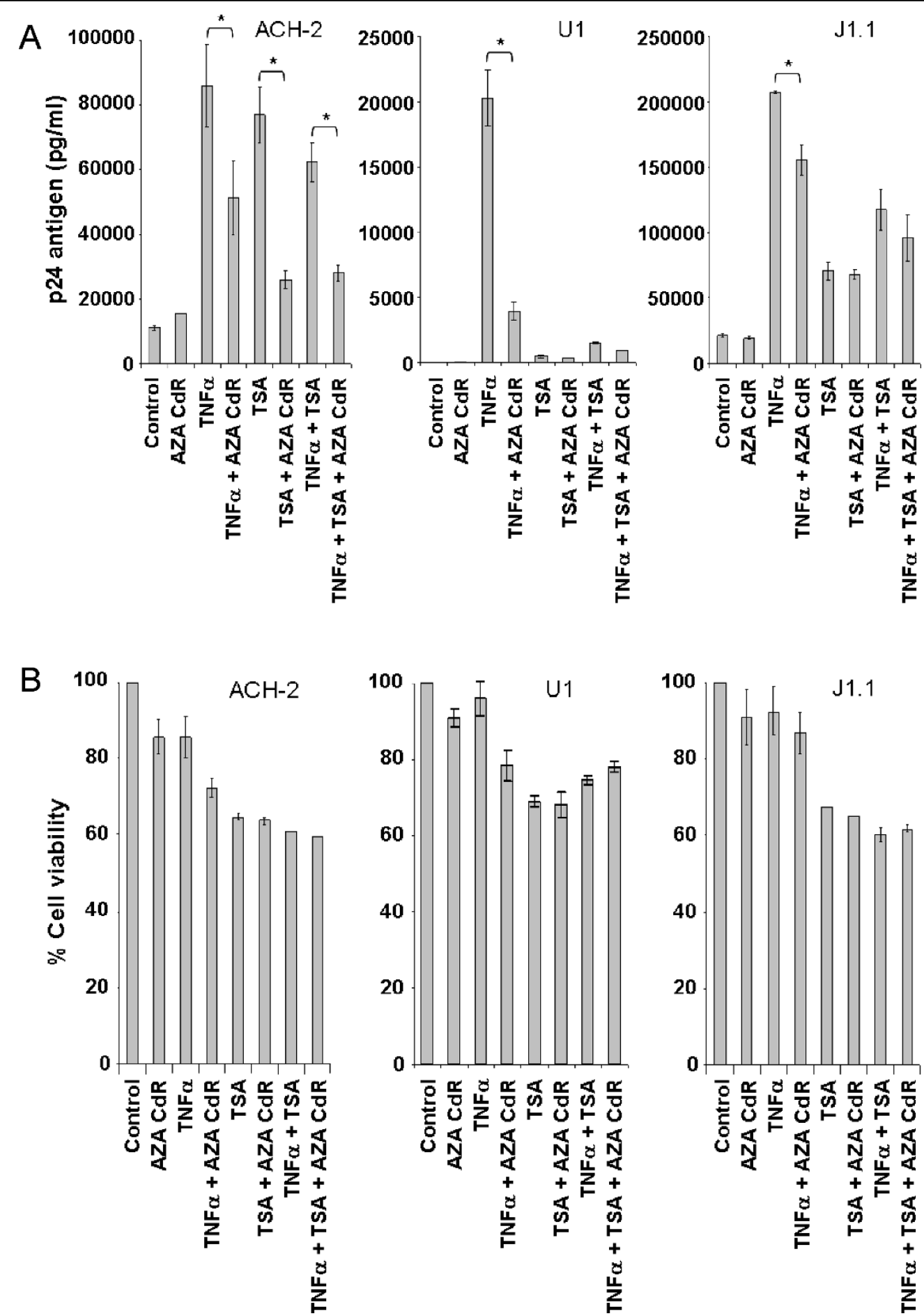

Figure 4 HIV activation by TNF $\alpha$ and TSA in ACH-2, U1, and J1.1 latently infected cell lines with or without Aza-CdR. A. p24 antigen production in ACH-2, U1 and $\mathrm{J1} .1$ cell lines for all treatments and treatment combinations at $48 \mathrm{~h}$ post-induction. Cells were cultured in RPMl with 10\% FBS. 2 million cells were treated with the different compounds for $48 \mathrm{~h}$. The compound order of addition was determined in Fig. 1. After $48 \mathrm{~h}$, cells were pelleted at $1400 \mathrm{rpm}$ for $7 \mathrm{~min}$ and discarded. Supernatants from the different treatment conditions were stored at $-80^{\circ} \mathrm{C}$ until further use. p24 antigen was determined using ELISA (Perkin Elmer, Waltham, MA) from the stored supernatants. B. Cell viability of the different treatments and treatment combinations shown in panel A, determined with an MTS assay (Promega, Madison, WI) at $48 \mathrm{~h}$ posttreatment. Compound final concentrations of the activators were Aza-CdR $(2.5 \mu \mathrm{M})$, TNF $\alpha(10 \mathrm{ng} / \mathrm{ml})$ and TSA $(1.5 \mu \mathrm{M})$. Results are the mean \pm standard deviation (SD). Statistical analysis (Student's t-test) was performed using STATA software package (StataCorp LP, College Station, TX), ${ }^{*} p \leq 0.05$. 
Table 1 Effect of AZA-CdR in TNF $\alpha$ HIV latently infected cell activation

\begin{tabular}{|c|c|c|c|c|c|}
\hline & & Control & AZA-CdR & TNF $\alpha$ & TNF $\alpha+A Z A-C d R$ \\
\hline \multirow[t]{7}{*}{ J-Lat } & 6.3 & $0.0 \pm 0.0$ & $62 \pm 0.6$ & $\begin{array}{c}23136 \pm \\
5060\end{array}$ & $60090 \pm 3090$ \\
\hline & 8.4 & $0.0 \pm 0.0$ & $0.0 \pm 0.0$ & $1613 \pm 485$ & $22427 \pm 4215$ \\
\hline & 9.2 & $30 \pm 0.8$ & $83 \pm 4$ & $\begin{array}{c}26490 \pm \\
2798\end{array}$ & $78921 \pm 13057$ \\
\hline & 10.6 & $80 \pm 10$ & $190 \pm 48$ & $\begin{array}{c}87578 \pm \\
1071\end{array}$ & $58164 \pm 5693$ \\
\hline & $\mathrm{ACH}-2$ & $\begin{array}{c}11083 \pm \\
670\end{array}$ & $\begin{array}{c}15445 \pm \\
12\end{array}$ & $\begin{array}{c}85997 \pm \\
12654\end{array}$ & $51347 \pm 11353$ \\
\hline & U1 & $12 \pm 1$ & $44 \pm 5$ & $\begin{array}{c}20305 \pm \\
2150\end{array}$ & $3943 \pm 687$ \\
\hline & J1.1 & $\begin{array}{c}21475 \pm \\
1475\end{array}$ & $\begin{array}{c}19577 \pm \\
1335\end{array}$ & $\begin{array}{c}207468 \pm \\
890\end{array}$ & $155646 \pm 11578$ \\
\hline
\end{tabular}

Mean p24 (pg/ml) \pm standard deviation.

In HIV infected patients, the latently infected cells harbor many different proviruses. While the frequency of latently infected cells in the periphery is low, perhaps 1 in $10^{6}$ cells, the total number of latently infected cells within a patient has been estimated to be as high as $10^{6}-10^{7}$ total cells [59]. The latently infected lines we examined may not be completely representative of latently infected cells as they exist in vivo, but the great potential variability in host cell chromosomal location and epigenetic and transcriptional environments of proviruses from as many as $10^{6}-10^{7}$ total latently infected cells suggests that, at least for some latently infected cells that exist in vivo, DNMTIs and HDACIs may inhibit HIV activation, as we describe here. While it is clear that DNMTIs and HDACIs offer promise as agents to attack the reservoir, our findings suggest that it may be necessary to carefully optimize HIV activation strategies so that some treatment or combination of treatments is active across large numbers of latently infected cells. For effective clinical applications, fairly elaborate combinations of activators and co-activators may be required to assure that essentially all proviruses are induced into active replication.

\begin{abstract}
Abbreviations
Aza-CdR: 5-aza-2'deoxycytidine; DNMT: DNA methyltransferase DNMTI: DNMT inhibitor; GFP: green fluorescent protein; HAART: highly active antiretroviral therapy; HDAC: histone deacetylase; HDACl: HDAC inhibitor; HIV-1: Human Immunodeficiency Virus type I; LTR: Long Terminal Repeat; MTS: 3-(4,5dimethylthiazol-2-yl)-5-(3-carboxymethoxyphenyl)-2-(4-sulfophenyl)-2Htetrazolium, inner salt; SAHA: suberoylanilide hydroxamic acid; TAR: Transactivation response element; TNF $\alpha$ : tumor necrosis factor alpha; TPA: 12-Otetradecanoylphorbol-13-acetate; TSA: trichostatin A
\end{abstract}

\section{Acknowledgements}

This work was funded in part by a Children's Research Institute, Children's National Medical Center Research Advisory Committee award to SZ and by the District of Columbia Developmental Center for AIDS Research (DC CFAR). GF is a Beatriu de Pinos Fellow of the Departament d'Universitats, Recerca i
Societat de la Informació de la Generalitat de Catalunya. The following reagents were obtained through the AIDS Research and Reference Reagent Program, Division of AIDS, NIAID, NIH: J-Lat full length Clones 6.3, 8.4, 9.2 and 10.6 from Dr. Eric Verdin, ACH-2, J1.1 and U1/HIV-1 from Dr. Thomas Folks.

\section{Author details}

${ }^{1}$ Center for Cancer and Immunology Research, Children's Research Institute, Children's National Medical Center, Washington DC, USA. ²Departments of Pediatrics and Microbiology, Immunology, and Tropical Medicine, George Washington University School of Medicine, Washington DC, USA.

\section{Authors' contributions}

GF carried out the experiments, data analysis and drafted the manuscript. SZ participated in the design of the study and data analysis, and drafted the manuscript. All authors read and approved the final manuscript.

\section{Competing interests}

The authors declare that they have no competing interests.

Received: 30 June 2010 Accepted: 13 October 2010

Published: 13 October 2010

\section{References}

1. Bukrinsky M, Stanwick T, Dempsey M, Stevenson M: Quiescent T lymphocytes as an inducible virus reservoir in HIV-1 infection. Science 1991, 254:423-427.

2. Chun TW, Stuyver L, Mizell SB, Ehler LA, Mican JA, Baseler M, Lloyd AL, Nowak MA, Fauci AS: Presence of an inducible HIV-1 latent reservoir during highly active antiretroviral therapy. Proc Natl Acad Sci USA 1997, 94:13193-13197.

3. Finzi D, Hermankova M, Pierson T, Carruth LM, Buck C, Chaisson RE, Quinn TC, Chadwick K, Margolick J, Brookmeyer R, et al: Identification of a reservoir for HIV-1 in patients on highly active antiretroviral therapy. Science 1997, 278:1295-1300.

4. Wong JK, Hezareh M, Gunthard HF, Havlir DV, Ignacio CC, Spina CA, Richman DD: Recovery of replication-competent HIV despite prolonged suppression of plasma viremia. Science 1997, 278:1291-1295.

5. Dinoso JB, Kim SY, Wiegand AM, Palmer SE, Gange SJ, Cranmer L, O'Shea A, Callender M, Spivak A, Brennan T, et al: Treatment intensification does not reduce residual HIV-1 viremia in patients on highly active antiretroviral therapy. Proc Natl Acad Sci USA 2009, 106:9403-9408.

6. Colin L, Van Lint C: Molecular control of HIV-1 postintegration latency: implications for the development of new therapeutic strategies. Retrovirology 2009, 6:111.

7. Richman DD, Margolis DM, Delaney M, Greene WC, Hazuda D, Pomerantz RJ: The challenge of finding a cure for HIV infection. Science 2009, 323:1304-1307.

8. Dahl V, Josefsson L, Palmer S: HIV reservoirs, latency, and reactivation: prospects for eradication. Antiviral Res 2010, 85:286-294.

9. Coiras M, Lopez-Huertas MR, Perez-Olmeda M, Alcami J: Understanding HIV-1 latency provides clues for the eradication of long-term reservoirs. Nat Rev Microbiol 2009, 7:798-812.

10. Marsden MD, Zack JA: Eradication of HIV: current challenges and new directions. J Antimicrob Chemother 2009, 63:7-10.

11. Geeraert L, Kraus G, Pomerantz RJ: Hide-and-seek: the challenge of viral persistence in HIV-1 infection. Annu Rev Med 2008, 59:487-501.

12. Hamer DH: Can HIV be Cured? Mechanisms of HIV persistence and strategies to combat it. Curr HIV Res 2004, 2:99-111.

13. Kulkosky J, Culnan DM, Roman J, Dornadula G, Schnell M, Boyd MR Pomerantz RJ: Prostratin: activation of latent HIV-1 expression suggests a potential inductive adjuvant therapy for HAART. Blood 2001, 98:3006-3015.

14. Dybul M, Hidalgo B, Chun TW, Belson M, Migueles SA, Justement JS, Herpin B, Perry C, Hallahan CW, Davey RT, et al: Pilot study of the effects of intermittent interleukin-2 on human immunodeficiency virus (HIV)specific immune responses in patients treated during recently acquired HIV infection. J Infect Dis 2002, 185:61-68.

15. Chun TW, Engel D, Mizell SB, Hallahan CW, Fischette M, Park S, Davey RT Jr, Dybul M, Kovacs JA, Metcalf JA, et al: Effect of interleukin-2 on the pool of latently infected, resting CD4+ T cells in HIV-1-infected patients receiving highly active anti-retroviral therapy. Nat Med 1999, 5:651-655. 
16. Stellbrink HJ, van Lunzen J, Westby M, O'Sullivan E, Schneider C, Adam A, Weitner L, Kuhlmann B, Hoffmann C, Fenske S, et al: Effects of interleukin-2 plus highly active antiretroviral therapy on HIV-1 replication and proviral DNA (COSMIC trial). AIDS 2002, 16:1479-1487.

17. Wang FX, Xu Y, Sullivan J, Souder E, Argyris EG, Acheampong EA, Fisher J, Sierra M, Thomson MM, Najera R, et al: IL-7 is a potent and proviral strainspecific inducer of latent HIV-1 cellular reservoirs of infected individuals on virally suppressive HAART. J Clin Invest 2005, 115:128-137.

18. Lehrman G, Ylisastigui L, Bosch RJ, Margolis DM: Interleukin-7 induces HIV type 1 outgrowth from peripheral resting CD4+ T cells. J Acquir Immune Defic Syndr 2004, 36:1103-1104.

19. Chun TW, Engel D, Mizell SB, Ehler LA, Fauci AS: Induction of HIV-1 replication in latently infected CD4+ T cells using a combination of cytokines. J Exp Med 1998, 188:83-91.

20. Lafeuillade A, Poggi C, Chadapaud S, Hittinger G, Chouraqui M, Pisapia M, Delbeke E: Pilot study of a combination of highly active antiretroviral therapy and cytokines to induce HIV-1 remission. J Acquir Immune Defic Syndr 2001, 26:44-55.

21. Chun TW, Davey RT Jr, Engel D, Lane HC, Fauci AS: Re-emergence of HIV after stopping therapy. Nature 1999, 401:874-875.

22. Van Lint C, Emiliani S, Ott M, Verdin E: Transcriptional activation and chromatin remodeling of the HIV-1 promoter in response to histone acetylation. Embo J 1996, 15:1112-1120

23. Sheridan $P L$, Mayall $T P$, Verdin $E$, Jones KA: Histone acetyltransferases regulate HIV-1 enhancer activity in vitro. Genes Dev 1997, 11:3327-3340.

24. Archin NM, Espeseth A, Parker D, Cheema M, Hazuda D, Margolis DM: Expression of latent HIV induced by the potent HDAC inhibitor suberoylanilide hydroxamic acid. AIDS Res Hum Retroviruses 2009, 25:207-212

25. Bohan C, York D, Srinivasan A: Sodium butyrate activates human immunodeficiency virus long terminal repeat-directed expression. Biochem Biophys Res Commun 1987, 148:899-905.

26. Laughlin M, Zeichner S, Kolson D, Alwine J, Seshamma T, Pomerantz R, Gonzalez-Scaran F: Sodium butryate treatment of cells latently infected with HIV-1 results in the expression of unspliced viral RNA. Virology 1993, 196:496-505

27. Moog C, Kuntz-Simon G, Caussin-Schwemling C, Obert G: Sodium valproate, an anticonvulsant drug, stimulates human immunodeficiency virus type 1 replication independently of glutathione levels. J Gen Virol 1996, 77(Pt 9):1993-1999.

28. Archin NM, Eron JJ, Palmer S, Hartmann-Duff A, Martinson JA, Wiegand A, Bandarenko N, Schmitz JL, Bosch RJ, Landay AL, et al: Valproic acid without intensified antiviral therapy has limited impact on persistent HIV infection of resting CD4+ T cells. AIDS 2008, 22:1131-1135.

29. Kauder SE, Bosque A, Lindqvist A, Planelles V, Verdin E: Epigenetic regulation of HIV-1 latency by cytosine methylation. PLoS Pathog 2009, 5: e1000495.

30. Quivy V, Adam E, Collette Y, Demonte D, Chariot A, Vanhulle C, Berkhout B, Castellano $R$, de Launoit $Y$, Burny $A$, et al: Synergistic activation of human immunodeficiency virus type 1 promoter activity by NF-kappaB and inhibitors of deacetylases: potential perspectives for the development of therapeutic strategies. J Virol 2002, 76:11091-11103.

31. Yedavalli VR, Jeang KT: Methylation: a regulator of HIV-1 replication? Retrovirology 2007, 4:9.

32. Savarino A, Mai A, Norelli S, El Daker S, Valente S, Rotili D, Altucci L, Palamara AT, Garaci E: "Shock and kill" effects of class I-selective histone deacetylase inhibitors in combination with the glutathione synthesis inhibitor buthionine sulfoximine in cell line models for HIV-1 quiescence. Retrovirology 2009, 6:52.

33. Verdin $E$, Paras $P \mathrm{Jr}$, Van Lint $\mathrm{C}$ : Chromatin disruption in the promoter of human immunodeficiency virus type 1 during transcriptional activation. Embo J 1993, 12:3249-3259.

34. El Kharroubi A, Piras G, Zensen R, Martin MA: Transcriptional activation of the integrated chromatin-associated human immunodeficiency virus type 1 promoter. Mol Cell Biol 1998, 18:2535-2544.

35. Benkirane M, Chun RF, Xiao H, Ogryzko W, Howard BH, Nakatani Y, Jeang KT: Activation of integrated provirus requires histone acetyltransferase. p300 and P/CAF are coactivators for HIV-1 Tat. J Biol Chem 1998, 273:24898-24905.

36. Marban C, Suzanne S, Dequiedt F, de Walque $S$, Redel L, Van Lint C, Aunis $D$, Rohr $O$ : Recruitment of chromatin-modifying enzymes by
CTIP2 promotes HIV-1 transcriptional silencing. EMBO J 2007, 26:412-423.

37. Jiang G, Espeseth A, Hazuda DJ, Margolis DM: c-Myc and Sp1 contribute to proviral latency by recruiting histone deacetylase 1 to the human immunodeficiency virus type 1 promoter. J Virol 2007, 81:10914-10923.

38. Coull JJ, He G, Melander C, Rucker VC, Dervan PB, Margolis DM: Targeted derepression of the human immunodeficiency virus type 1 long terminal repeat by pyrrole-imidazole polyamides. J Virol 2002, 76:12349-12354

39. Lusic M, Marcello A, Cereseto A, Giacca M: Regulation of HIV-1 gene expression by histone acetylation and factor recruitment at the LTR promoter. Embo J 2003, 22:6550-6561

40. Hejnar J, Hajkova P, Plachy J, Elleder D, Stepanets V, Svoboda J: CpG island protects Rous sarcoma virus-derived vectors integrated into nonpermissive cells from DNA methylation and transcriptional suppression. Proc Natl Acad Sci USA 2001, 98:565-569.

41. Taniguchi Y, Nosaka K, Yasunaga J, Maeda M, Mueller N, Okayama A, Matsuoka M: Silencing of human T-cell leukemia virus type I gene transcription by epigenetic mechanisms. Retrovirology 2005, 2:64.

42. Lorincz MC, Schubeler D, Groudine M: Methylation-mediated proviral silencing is associated with MeCP2 recruitment and localized histone $\mathrm{H} 3$ deacetylation. Mol Cell Biol 2001, 21:7913-7922.

43. Curradi M, Izzo A, Badaracco G, Landsberger N: Molecular mechanisms of gene silencing mediated by DNA methylation. Mol Cell Biol 2002, 22:3157-3173.

44. Blazkova J, Trejbalova K, Gondois-Rey F, Halfon P, Philibert P, Guiguen A, Verdin E, Olive D, Van Lint C, Hejnar J, Hirsch I: CpG methylation controls reactivation of HIV from latency. PLoS Pathog 2009, 5:e1000554.

45. Jeeninga RE, Westerhout EM, van Gerven ML, Berkhout B: HIV-1 latency in actively dividing human T cell lines. Retrovirology 2008, 5:37.

46. Jordan A, Bisgrove D, Verdin E: HIV reproducibly establishes a latent infection after acute infection of T cells in vitro. Embo J 2003, 22:1868-1877.

47. Perez VL, Rowe T, Justement JS, Butera ST, June CH, Folks TM: An HIV-1infected T cell clone defective in IL-2 production and Ca2+ mobilization after CD3 stimulation. J Immunol 1991, 147:3145-3148.

48. Clouse KA, Powell D, Washington I, Poli G, Strebel K, Farrar W, Barstad P, Kovacs J, Fauci AS, Folks TM: Monokine regulation of human immunodeficiency virus-1 expression in a chronically infected human T cell clone. J Immunol 1989, 142:431-438.

49. Folks TM, Justement J, Kinter A, Dinarello CA, Fauci AS: Cytokine-induced expression of HIV-1 in a chronically infected promonocyte cell line. Science 1987, 238:800-802.

50. Emiliani S, Van Lint C, Fischle W, Paras P Jr, Ott M, Brady J, Verdin E: A point mutation in the HIV-1 Tat responsive element is associated with postintegration latency. Proc Natl Acad Sci USA 1996, 93:6377-6381.

51. Emiliani S, Fischle W, Ott M, Van Lint C, Amella CA, Verdin E: Mutations in the tat gene are responsible for human immunodeficiency virus type 1 postintegration latency in the U1 cell line. J Virol 1998, 72:1666-1670.

52. Poli G, Kinter A, Justement JS, Kehrl JH, Bressler P, Stanley S, Fauci AS: Tumor necrosis factor alpha functions in an autocrine manner in the induction of human immunodeficiency virus expression. Proc Natl Acad SCi USA 1990, 87:782-785.

53. Verdin E: DNase I-hypersensitive sites are associated with both long terminal repeats and with the intragenic enhancer of integrated human immunodeficiency virus type 1. J Virol 1991, 65:6790-6799.

54. Karpf AR, Lasek AW, Ririe TO, Hanks AN, Grossman D, Jones DA: Limited gene activation in tumor and normal epithelial cells treated with the DNA methyltransferase inhibitor 5-aza-2'-deoxycytidine. Mol Pharmacol 2004, 65:18-27.

55. Yu JN, Xue CY, Wang XG, Lin F, Liu CY, Lu FZ, Liu HL: 5-AZA-2'deoxycytidine (5-AZA-CdR) leads to down-regulation of Dnmt1o and gene expression in preimplantation mouse embryos. Zygote 2009, 17:137-145.

56. Bender CM, Pao MM, Jones PA: Inhibition of DNA methylation by 5-aza$2^{\prime}$-deoxycytidine suppresses the growth of human tumor cell lines. Cancer Res 1998, 58:95-101.

57. Krishnan V, Zeichner SL: Alterations in the expression of DEAD-box and other RNA binding proteins during HIV-1 replication. Retrovirology 2004, $1: 42$. 
58. Krishnan V, Zeichner SL: Host cell gene expression during human immunodeficiency virus type 1 latency and reactivation and effects of targeting genes that are differentially expressed in viral latency. J Virol 2004, 78:9458-9473.

59. Chun TW, Carruth L, Finzi D, Shen X, DiGiuseppe JA, Taylor H,

Hermankova M, Chadwick K, Margolick J, Quinn TC, et al: Quantification of latent tissue reservoirs and total body viral load in HIV-1 infection. Nature 1997, 387:183-188.

doi:10.1186/1743-422X-7-266

Cite this article as: Fernandez and Zeichner: Cell line-dependent

variability in HIV activation employing DNMT inhibitors. Virology Journal 2010 7:266.

Submit your next manuscript to BioMed Central and take full advantage of:

- Convenient online submission

- Thorough peer review

- No space constraints or color figure charges

- Immediate publication on acceptance

- Inclusion in PubMed, CAS, Scopus and Google Scholar

- Research which is freely available for redistribution

Submit your manuscript at www.biomedcentral.com/submit
C Biomed Central 